Volume 8, No.6, November - December 2019

International Journal of Advanced Trends in Computer Science and Engineering

Available Online at http://www.warse.org/IJATCSE/static/pdf/file/ijatcse82862019.pdf

https://doi.org/10.30534/ijatcse/2019/82862019

\title{
Business Process based GNSS Modeling Method
}

\author{
Sang Young Lee ${ }^{1}$ \\ ${ }^{1}$ Namseoul University, South Korea, sylee@ nsu.ac.kr
}

\begin{abstract}
Business-oriented viewpoint, GNSS applications extract key components, which is utilized for building related applications. And, their software quality has to be improved in terms of development, maintenance, and productivity. In short, the GNSS component will have to be made of the self-execution unit that hierarchically modularizes functions provided by a system. By applying the reusable property, the component is developed by distinguishing between reusable and new one, which reduces its development time and secures quality component. To extract quality one, a systematic modeling method that accurately expresses user's demands is required.

In this paper suggests a modeling methodology to build a key business process-oriented system based on extraction of key components that is not limited to a certain domain. From this business-oriented perspective, major key components are extracted and applied to relevant application, which contributes to improved software quality such as development, maintenance, productivity, etc. To extract components, necessary functions for a system are classified functionally and hierarchically and modularized. From the process, the self-execution unit is produced for a meaningful service.. It does not use the existing procedure- or object-oriented system, a process-oriented component design method, but business-based modeling methodology, and it suggests a process to extract, define, and analyze components that are commonly used in relevant application domains which is a foundation for building GPS system.
\end{abstract}

Key words : Business Process, GNSS, Component, Modeling, Framework.

\section{INTRODUCTION}

Global Navigation Satellite System(GNSS) is a system to determine the position of satellite anytime and anywhere to receive satellite signal as a navigation system based on satellite. GPS (Global Positioning System) is invented for the military and developed by the Pentagon, but it is available for civilian use after opening the civil code (L1). GNSS includes US GPS, Russian GLONASS(Global Navigation Satellite
System), European Galileo, etc. Currently, GPS satellite such as Block II/IIA, Block IIR, Block IIR-M, and others are being used[1, 2].

In GNSS fields, developed countries such as the United States, Europe, and other countries are dedicated to secure the original technologies, including GNSS simulator, etc. that are available for trail test and evaluation [3]. Also, the technology is widely used for the military uses such as precise measurement, but also for civilian uses such as car navigation system, small lightweight GPS receiver for hiking $[4,5]$.

The basic principle of GNSS is to measure the propagation time that is considered to be the time the signal takes to travel from the satellite to the receive, calculate distance from satellite to receiver, and measure the current location using trigonometry. In these applications, the focus is that they are located on different domain, but it has common and key components. In other word, the existing applications have disadvantages in terms of separate implementation and development for each domain even though they have common components. Thus, from business-oriented viewpoint, GNSS applications extract key components, which is utilized for building related applications. And, their software quality has to be improved in terms of development, maintenance, and productivity. In short, the GNSS component will have to be made of the self-execution unit that hierarchically modularizes functions provided by a system. By applying the reusable property, the component is developed by distinguishing between reusable and new one, which reduces its development time and secures quality component. To extract quality one, a systematic modeling method that accurately expresses user's demands is required $[6,7,8]$.

In this paper aims to extract key components that is not limited to the specific domain and suggest a modeling method that is able to build business process-oriented system.

\section{RELATED WORKS}

By ensuring reusability and independence of software module, the component shows the new paradigm to solve problems of complexity and productivity of software. Various methodologies of developing UML - key methodology based on component - have been actively used in diverse fields, including development process, system engineering, and business process. $[9,10]$ 
Recent projects for GNSS component development process extracted components after requirement analysis of business components. Then, business components extracted by an interaction diagram are refined, and the components to be included in the system components that are extracted for defining architecture are found and combined[11, 12 13]. However, the method has an advantage in that its extraction clearly separate system and business components because it clearly defines the system component that can be functionally reused in respect of system service[14, 15, 16]. On the other hand, the method has disadvantages in that it is hard to discern whether the word in the type diagram has a meaning or not by a work-site operator who has no systemic concept and it is difficult to draw a relation between those words when the operator draws a type diagram to figure out business requirements[17, 18, 19].

In this paper, it does not use the existing procedure or object-oriented system, a process-oriented component design method, but business process-based modeling methodology, and it suggests a process to extract, define, and analyze components that are commonly used in relevant application domains which is a foundation for building GPS system to overcome these disadvantages.

\section{SYSTEM REQUIREMENT ANALYSIS}

Analysis of business requirements and extraction of business class models are required prior to developing an application. According to these requirements, mobile and reference stations receive signals from GPS satellite[20, 21]. The satellite continuously transmits information about time, its orbit, rough orbits of entire satellites, their reliability, and error correction factors that are required for other navigation system, and the receivers of mobile and reference stations continuously receive these message signals for navigation[22, $23,24,25]$.

The assignment table about requirements, actor, and use case is shown in Table 1.

Table 1: Assignment Table about Requirements, Actor, and Use Case

\begin{tabular}{|c|c|c|c|}
\hline No. & Requirements & Actor & Use case \\
\hline 1 & $\begin{array}{l}\text { The receivers of } \\
\text { mobile and reference } \\
\text { stations receive } \\
\text { signals from the GPS } \\
\text { satellite. The signal } \\
\text { contains information } \\
\text { about time, its own } \\
\text { orbit, rough orbits of } \\
\text { entire satellites, their } \\
\text { reliability, and error } \\
\text { correction factors that } \\
\text { are required for other }\end{array}$ & $\begin{array}{c}\square \text { Satellite } \\
\square \text { Mobile } \\
\text { Device }\end{array}$ & $\begin{array}{c}\square \text { Receive GPS } \\
\text { signal }\end{array}$ \\
\hline
\end{tabular}

\begin{tabular}{|c|c|c|c|}
\hline & navigation system. & & \\
\hline 2 & $\begin{array}{l}\text { The receiver of } \\
\text { mobile station } \\
\text { receives signals from } \\
\text { GPS satellite and } \\
\text { processes data. And } \\
\text { then, using the signal, } \\
\text { the location of mobile } \\
\text { station is measured, } \\
\text { orbital information } \\
\text { relating the satellite is } \\
\text { extracted, and rough } \\
\text { information of orbit } \\
\text { such as the number of } \\
\text { satellites and the } \\
\text { satellite number that } \\
\text { is used is extracted. In } \\
\text { addition, the receiver } \\
\text { extracts the time to } \\
\text { receive signals from } \\
\text { the GPS satellite. }\end{array}$ & $\begin{array}{l}\square \text { Mobile } \\
\text { Device }\end{array}$ & $\begin{array}{c}\square \text { Process GPS } \\
\text { data } \\
\square \text { Measure } \\
\text { mobile } \\
\text { location } \\
\square \text { Extract orbit } \\
\text { information } \\
\square \text { Extract } \\
\text { receiving } \\
\text { information }\end{array}$ \\
\hline 3 & $\begin{array}{l}\text { The mobile station } \\
\text { transmits processed } \\
\text { data to the control } \\
\text { station, including its } \\
\text { location, satellite } \\
\text { number, the number } \\
\text { of satellites, time to } \\
\text { receive signal from } \\
\text { the satellite, location } \\
\text { of other satellites, and } \\
\text { speed that is } \\
\text { calculated with } \\
\text { speedometer in the } \\
\text { mobile station. It also } \\
\text { transmits its own } \\
\text { unique ID, } \\
\text { information and its } \\
\text { condition to the } \\
\text { control station. }\end{array}$ & $\begin{array}{l}\square \text { Mobile } \\
\text { Device } \\
\square \text { Control } \\
\text { Station }\end{array}$ & $\begin{array}{c}\square \text { Transfer GPS } \\
\text { data } \\
\square \text { Transfer } \\
\text { mobile } \\
\text { station } \\
\text { information } \\
\square \text { Transfer } \\
\text { Processed } \\
\text { data }\end{array}$ \\
\hline 4 & $\begin{array}{l}\text { The reference station } \\
\text { calculates error based } \\
\text { on the signal from } \\
\text { GPS satellite. The } \\
\text { calculated results are } \\
\text { exported to RTCM } \\
\text { format. }\end{array}$ & $\begin{array}{c}\square \text { Control } \\
\text { Station } \\
\square \text { Base } \\
\text { Device }\end{array}$ & $\begin{array}{l}\square \text { Compute } \\
\text { correction } \\
\text { data } \\
\square \text { Set RTCM } \\
\text { format }\end{array}$ \\
\hline 5 & $\begin{array}{l}\text { The reference station } \\
\text { transmits the } \\
\text { correction value of } \\
\text { each satellite in } \\
\text { RTCM format. }\end{array}$ & $\begin{array}{c}\square \text { Control } \\
\text { Station } \\
\square \text { Base } \\
\text { Device }\end{array}$ & $\begin{array}{c}\square \text { Transfer } \\
\text { correction } \\
\text { data }\end{array}$ \\
\hline
\end{tabular}




\begin{tabular}{|c|c|c|c|}
\hline 6 & $\begin{array}{l}\text { The location of } \\
\text { mobile station is } \\
\text { calculated by using } \\
\text { the correction value } \\
\text { in RTCM format } \\
\text { obtained from the } \\
\text { reference station and } \\
\text { information about } \\
\text { location and satellite } \\
\text { obtained from the } \\
\text { mobile station. }\end{array}$ & $\begin{array}{l}\square \text { System } \\
\text { Manager }\end{array}$ & $\begin{array}{c}\square \text { Compute } \\
\text { mobile } \\
\text { location }\end{array}$ \\
\hline 7 & $\begin{array}{l}\text { The control station } \\
\text { manages databases } \\
\text { when addition, } \\
\text { modifying, or } \\
\text { deleting them, } \\
\text { analyzes the log and } \\
\text { results of mobile } \\
\text { station, and then } \\
\text { extract their statistics. }\end{array}$ & $\begin{array}{l}\square \text { System } \\
\text { Manager }\end{array}$ & $\begin{array}{c}\square \text { Manage } \\
\text { mobile } \\
\text { station } \\
\square \text { Manage } \\
\text { database } \\
\square \text { Extract } \\
\text { analysis } \\
\text { and statistics }\end{array}$ \\
\hline 8 & $\begin{array}{l}\text { A system administer } \\
\text { manages information } \\
\text { about users, and the } \\
\text { user is authorized to } \\
\text { access the system by } \\
\text { making ID and } \\
\text { password. }\end{array}$ & $\begin{array}{l}\square \text { System } \\
\text { Manager }\end{array}$ & $\begin{array}{c}\square \text { Manage } \\
\text { control } \\
\text { user } \\
\square \text { Manage } \\
\text { authentication } \\
\square \text { Manage user } \\
\text { information }\end{array}$ \\
\hline 9 & $\begin{array}{l}\text { When a user requests } \\
\text { information about the } \\
\text { mobile station, the } \\
\text { control station } \\
\text { provides information } \\
\text { about location, speed, } \\
\text { and time of the mobile } \\
\text { station, then marks or } \\
\text { analyzes its trace. }\end{array}$ & $\square$ User & $\begin{array}{c}\square \text { Request } \\
\text { information } \\
\square \text { Provide } \\
\text { information }\end{array}$ \\
\hline
\end{tabular}

The extraction rule of major use cases is as follows. Major use cases only related to success of a scenario. If an exception occurred while processing the use case scenario and the use cases that do not concerns flows, the use cases are not regarded as a successful use case. From the relevant business process perspective, scenario are as follows.

- The receivers of mobile and reference stations continuously receive the navigation message signals, which is information about time, its own orbit, rough orbits of entire satellites, their reliability, and error correction factors that are required for other navigation system.

Extensions : If the receiver does not receive a signal, it will be an error. It prepares to receive signals by back into the situation that can receive the signal.

- Using the signal from GPS satellite, the location of mobile station is measured, orbital information relating the satellite is extracted, and rough information of orbit such as the number of satellites and the satellite number that is used is extracted. In addition, the receiver extracts the time to receive signals from the GPS satellite.

Extensions : If the receiver does not process the data, it receives the signal from the satellite again and processes the data.

- The mobile station transmits processed data to the control station, including its location, satellite number, the number of satellites, time to receive signal from the satellite, location of other satellites, and speed that is calculated with speedometer in the mobile station. It also transmits its own unique ID, information and its condition to the control station.

Extensions : If transmission is failed, it transmits data again.

- The reference station calculates the correction value of each satellite after comparing signal with the received signal, by using precisely known value of location of the reference station, and the results are exported into RTCM format which is a standard format.

- The reference station calculates the correction value of each satellite after comparing signal with the received signal, by using precisely known value of location of the reference station. It transmits the calculated RTCM error information to the control station. At this time, all error information is transmitted.

Extensions : If transmission is failed, it transmits data agian.

- The control station calculates the correct location of the mobile station by using the correction value in RTCM format obtained from the reference station and information about location and satellite obtained from the mobile station.

Extensions : If the control station does not measure the location of mobile station, it sends an error message and obtain information again.

- The control station manages databases when addition, modifying, or deleting them, analyzes the log and results of mobile station, and then extract their statistics.

Extensions : When an authorized user accesses to the system, it will be considered as an exception by the system administer.

- The user of the control station should make ID and password to access the system, and the administer manages information about users.

Extensions : When an authorized user accesses to the system, it will be considered as an exception by the system administer.

- For users, the control station provides information about the mobile station such as location, speed, altitude, and the data that has a mark of orbits or analyzes the orbits.

Extensions : The information relating to the mobile station is changing in real time. If there is any change, new information should be provided.

In this scenario, the use cases of manage mobile station and manage control user are successful ones. However, these use 
cases are considered as unimportant ones, so they should be removed from the successful use cases.

\section{EXTRACTION OF SYSTEM INTERFACE}

In most cases, the common server logic can be figured out during refinement of use cases which is one of analysis steps, but in some case, it can be figured out during design steps, including interface layout or interface navigation design procedure. In this case, as with the method for common use cases, the object of the component can have properties of application component or business component.

The mapping relationship between the extracted use cases and system interface is shown in table 2 .

Table 2: Mapping Relationship between the Extracted Use Cases and System Interface

\begin{tabular}{|c|c|}
\hline Aleceive GPS sianal & $\begin{array}{c}\text { 〈Interface) } \\
\text { IFeceiveGPSsiganal }\end{array}$ \\
\hline [UC 1] Fecewe GPS signal & Intertace : FlecorreGPSSgrel \\
\hline Procens cops data & $\begin{array}{c}\text { (Intertace) } \\
\text { IProcessGGPSData }\end{array}$ \\
\hline luC 21 Process GPS data & Intsiace : ProcesesGPSData \\
\hline Transter cops data & $\begin{array}{c}\text { Unterface) } \\
\text { ITransterCPSData }\end{array}$ \\
\hline ACC 31 Trander Ges dita & Interface = FraneferGPSOata \\
\hline Compule correction data & $\begin{array}{c}\text { (Interface) } \\
\text { KComputeConectionData }\end{array}$ \\
\hline fuC 4) Compube correction cata & Fterface : 1 ComouteComection Data \\
\hline
\end{tabular}

To extract system components, it does consider not only the use cases that has sematic correlation, but the common class that is included in each use case. The process to precisely extract system components should be included.

At first, the range of the business class model is determined. As shown in Figure 1, delete the class that has no relation and decide the range of the model.

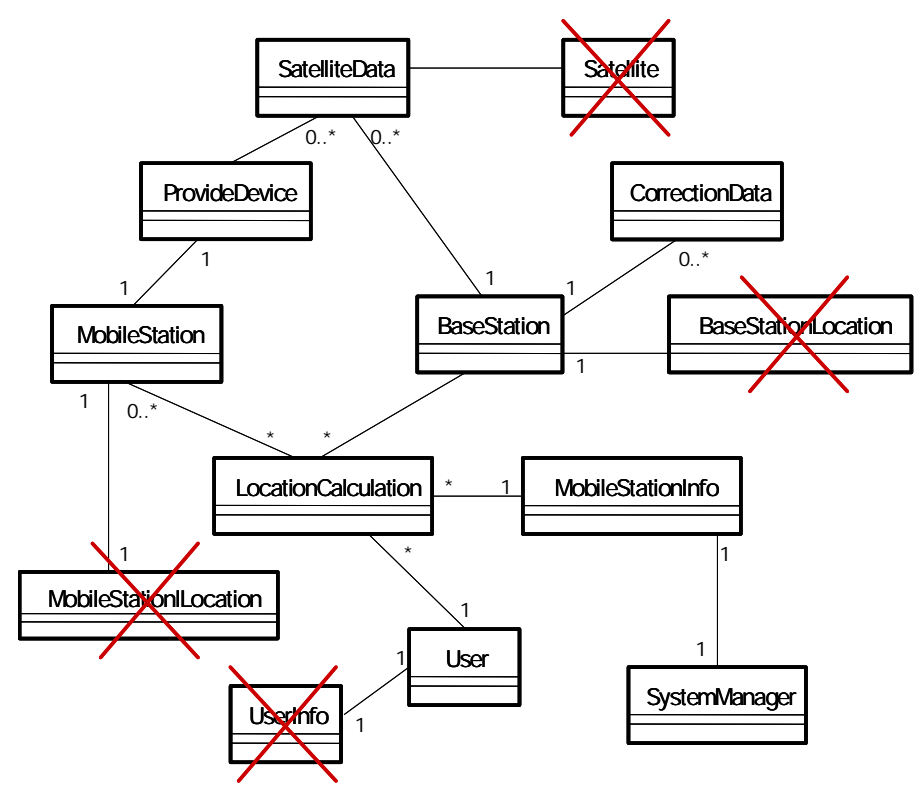

Figure 1: Determine Business Class Model Scope

As shown in Figure 2, extracted stereotype of key classes is expressed as $\langle<$ core $>>$ to indicate the business class model.

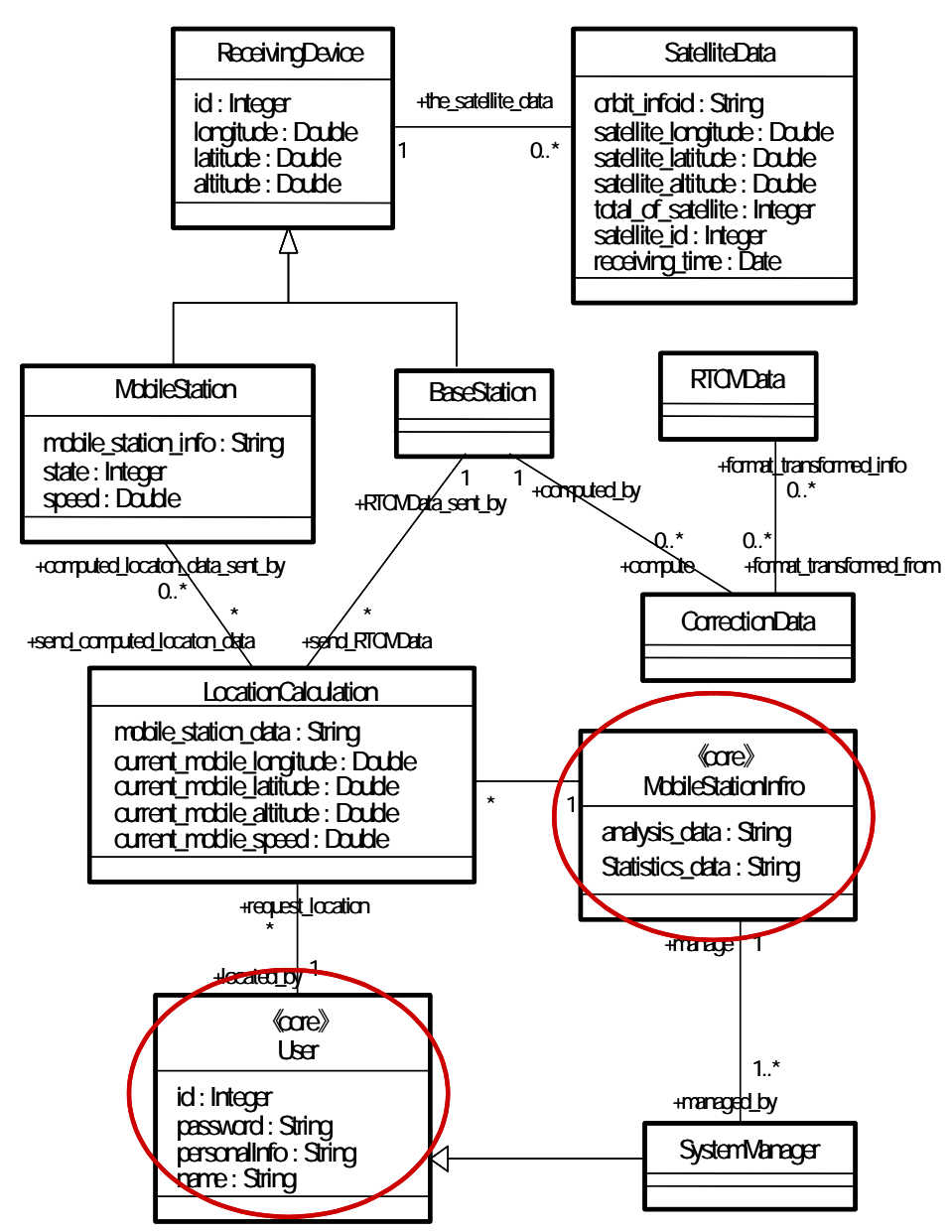

Figure 2 : Business class model representing the extracted core classes 
The diagram that represents relationship between extracted key classes and corresponding interface is shown in Figure 3.

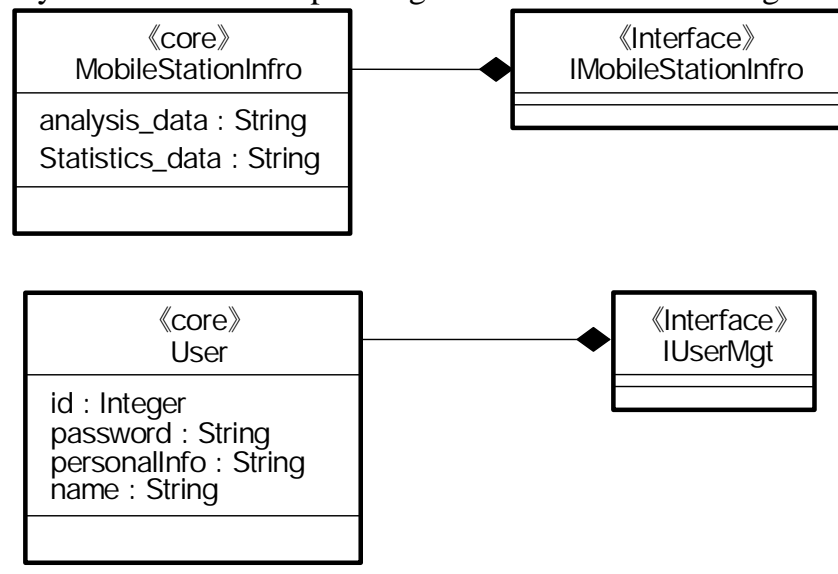

Figure 3 : Business class model representing the extracted core classes

As shown in the figure, the system interfaces, including IReceveGPSSignal, IProcessGPSData, and ITransferGPSData, for use cases related to the system of mobile station are specified as one component after considering the range of entire systems with systems of mobile, reference, and control stations. These interfaces can suggest one component specification because they have complex interaction and need to be processed for their interaction. Also, ICompute CorrectionData and ITransferCorrectionData that are the system interfaces of use cases relating to the system of the reference station would be one component. As they also have complex interaction between interfaces, and the data should be processed for the interaction, one component specification can be suggested.

The Figure 6 shows the component diagram that considers dependency between components drawn through such processes.

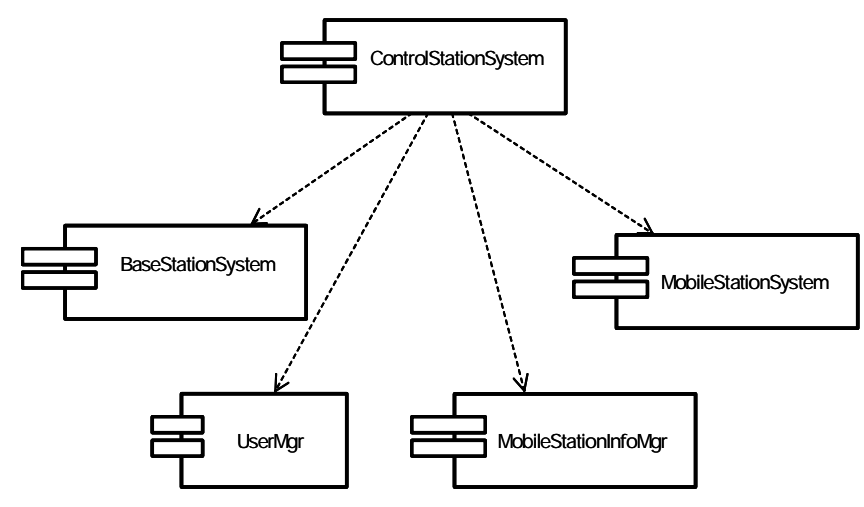

Figure 4 : Component Diagram

As shown in the figure, five components are extracted, which includes ControlStationSystem, BaseStationSystem, MobileStationSystem, UserMgr, and MobileStationInfoMgr components. ControlStationSystem component calculates real location of the mobile station by using information from the reference and mobile station and provides its information that the user requested. BaseStationSystem component calculates the error correction value, and MobileStationSystem component calculate the location of the mobile station by using the data from the satellite. UserMgr component provides the ability to manage users' information, and MobileStationInfoMgr component provides the ability to manage information about the mobile station. The components extracted from the such processes have a higher level of granularity, and they are able to be divided into several components with a lower level of granularity. In addition, special functions of a specific application would be extracted as additional components later. When building GPS application, the extracted components are able to be used by assembling them to match with a specific application. Because it has advantages not to affect other components and to modify a certain component when adding a specific function, the application can be built more efficiently.

\section{CONCLUSION}

To develop GPS system from the business perspective, this paper suggests a modeling methodology to build a key business process-oriented system based on extraction of key components that is not limited to a certain domain. Although there are disadvantages of the existing development methods of application in that there are common modules between domains, it makes up for in disadvantages, which is implementing and developing functions in the separate domain due to ease of development. From this business-oriented perspective, major key components are extracted and applied to relevant application, which contributes to improved software quality such as development, maintenance, productivity, etc. To extract components, necessary functions for a system are classified functionally and hierarchically and modularized. From the process, the self-execution unit is produced for a meaningful service. This study suggests a modeling method, which is that the component is developed by distinguishing between reusable and new one by applying the reusable property, which reduces its development time and secures quality component. It does not use the existing procedure- or object-oriented system, a process-oriented component design method, but business-based modeling methodology, and it suggests a process to extract, define, and analyze components that are commonly used in relevant application domains which is a foundation for building GPS system.

From the processes, as it would be built based on standardized frameworks and rules, it is possible to produce the desired product depending on requirement for each function. Therefore, if the software is built based on components, it has the advantage of improving software quality such as development, maintenance, productivity, etc.

\section{ACKNOWLEDGEMENT}

Funding for this paper was provided by Namseoul university 


\section{REFERENCES}

1. Pelgrum, W., Y. Morton, F. van Graas, S. Gunawardena1, M. Bakich, D. Charney, S. Peng, J. Triplett, A. Vermuru, P. Vikram, Measurement and analysis of artificially-generated and natural ionosphere scintillations effects on GNSS signals, Proc. ION ITM, San Diego, CA, Jan. 2011.

2. Vikram, P., Y. Morton, W. Pelgrum, Event driven data collection system for studying ionosphere scintillation, Proc. ION GNSS, Portland, OR, Sept. 2011.

3. Van Dierendonck, A. J., B. Arbesser-Rastburg, Measuring Ionospheric Scintillation in the Equatorial Region Over Africa, Including Measurements From SBAS Geostationary Satellite Signals, Proc. ION GNSS, Long Beach, CA, Sept. 2004.

4. Pelgrum, W., Y. Morton, F. van Graas, P. Vikram, S. Peng, Multi-domain analysis of the impact on natural and man-made ionosphere scintillations on GNSS signal propagation, Proc. ION GNSS, Portland, OR, Sept. 2011.

5. Gunawardena, S., Z. Zhu, F. van Graas, Triple Frequency RF Front-End for GNSS Instrumentation Receiver Applications, Proc. ION GNSS, Savana, GA, Sept. 2008.

6. Peng, S., and Y. Morton, A USRP2-Based Multi-Constellation and Multi-Frequency GNSS Software Receiver for Ionosphere Scintillation Studies, Proc. ION ITM, San Diego, CA, Jan. 2010.

7. Vikram, P., Event driven data collection system for studying ionosphere scintillation, MS thesis, Miami University, 2011

8. T. Humphreys, M. Psiaki, P. Kintner, B. Ledvina, GPS carrier tracking loop performance in the presence of ionospheric scintillations, ION GNSS Long Beach CA, pp. 156-167, September 2005.

9. D. Xu, Y. T. Morton, A semi-open loop GNSS carrier tracking algorithm for monitoring strong equatorial scintillation, IEEE Transactions on Aerospace and Electronic Systems, vol. 54, no. 2, pp. 722-738, April 2018. https://doi.org/10.1109/TAES.2017.2764778

10. C. L. Rino, The Theory of Scintillation with Applications in Remote Sensing, Hoboken, NJ:IEEE and Wiley, 2011.

11. Y. Jiao, C. Rino, Y. Morton, C. Carrano, Scintillation simulation on equatorial GPS signals for dynamic platforms, ION GNSS+ Portland OR, pp. 1644-1657, September 2017. https://doi.org/10.33012/2017.15258

12. Y. Jiao, D. Xu, Y. Morton, C. Rino, Equatorial scintillation amplitude fading characteristics across the GPS frequency bands, Navigation: Journal of The Institute of Navigation, vol. 63, no. 3, pp. 267-281, 2016. https://doi.org/10.1002/navi.146

13. M. Zhang, J. Zhang, A fast satellite selection algorithm: beyond four satellites, IEEE Journal of Selected Topics in Signal Processing, vol. 3, no. 5, pp. 740-747, 2009. https://doi.org/10.1109/JSTSP.2009.2028381

14. A. Peng, G. Ou, G. Li, Fast satellite selection method for multi-constellation Global Navigation Satellite System under obstacle environments, IET Radar Sonar \& Navigation, vol. 8, no. 9, pp. 1051-1058, 2014. https://doi.org/10.1049/iet-rsn.2013.0387

15. A.-L. Tao, S.-S. Jan, Optimal Navigation with Multi-constellation GNSS: A Satellite Selection Algorithm, Proceedings of the 29th International Technical
Meeting of The Satellite Division of the Institute of Navigation (ION GNSS+ 2016), pp. 128-139, 2016.

16. N. Blanco-Delgado, D. D. Nunes, Satellite selection method for multi-constellation GNSS using convex geometry, IEEE Transactions on Vehicular Technology, vol. 59, no. 9, pp. 4289-4297, 2010.

https://doi.org/10.1109/TVT.2010.2072939

17. J. Vila-Valls, P. Closas, J. T. Curran, Performance analysis of multi-frequency GNSS carrier tracking for strong ionospheric scintillation mitigation, 2017 25th European Signal Processing Conference (EUSIPCO), pp. 2699-2703, 2017.

18. M. Z. H. Bhuiyan, E. S. Lohan, M. Renfors, Code tracking algorithms for mitigating multipath effects in fading channels for satellite-based positioning, EURASIP Journal on Advances in Signal Processing, vol. 2008, no. 1, pp. 1-17, 2007.

https://doi.org/10.1155/2008/863629

19. L. Lau, P. Cross, Development and testing of a new ray-tracing approach to GNSS carrier-phase multipath modelling, Journal of Geodesy, vol. 81, no. 11, pp. 713-732, 2007.

https://doi.org/10.1007/s00190-007-0139-z

20. N. Vagle, A. Broumandan, A. Jafamia-Jahromi, G. Lachapelle, Performance analysis of GNSS multipath mitigation using antenna arrays, The Journal of Global Positioning Systems, vol. 14 , no. 1 , pp. 4, 2016 https://doi.org/10.1186/s41445-016-0004-6

21. Aaron Don M. Africa, Francis Xavier Asuncion, Janos Lance Tiberio and Raymund Miguel Francisco A. Munchua, Sensor-based Traffic Control Network with Neural Network Based Control System, International Journal of Advanced Trends in Computer Science and Engineering, Vol 8(4), pp.983-989, 2019 https://doi.org/10.30534/ijatcse/2019/01842019

22. Syrotenko Anatolii, Oleksandr Sotnikov, Maksym Iasechko, Volodymyr Larin, Svitlana Iasechko, Oleksandr Ochkurenko and Andriy Volkov, Model of Combined Solid Plasma Material for the Protection of Radio-Electronic Means of Optical and Radio Radiation, International Journal of Advanced Trends in Computer Science and Engineering, Vol 8(4), pp.1241-1247, 2019 https://doi.org/10.30534/ijatcse/2019/33842019

23. M.Pandimadevi, R.Tamilselvi and M.Parisa Beham, Design Issues of Flexible Antenna -A Review, International Journal of Advanced Trends in Computer Science and Engineering , Vol 8(4), pp.1386-1394, 2019 https://doi.org/10.30534/ijatcse/2019/55842019

24. M.Pandimadevi, R.Tamilselvi and M.Parisa Beham, Design Issues of Flexible Antenna -A Review, International Journal of Advanced Trends in Computer Science and Engineering , Vol 8(4), pp.1386-1394, 2019 https://doi.org/10.30534/ijatcse/2019/55842019

25. Pooja Singh and Nasib Singh Gill, A Secure and Power-Aware Protocol for Wireless Ad Hoc Networks, International Journal of Advanced Trends in Computer Science and Engineering, Vol 8(1), pp.34-41, 2019 https://doi.org/10.30534/ijatcse/2019/07812019 